Jóvenes huérfanos en el Maestrazgo medieval: aproximación a su vida a través de los documentos de tutela

Joaquín Aparici Martí

Universitat Jaume I. Castelló

Concepción Villanueva Morte

Universidad de Zaragoza 



\title{
Jóvenes huérfanos en el Maestrazgo medieval: aproximación a su vida a través de los documentos de tutela
}

\section{Young orphans in the medieval Maestrazgo: an approach to their life through guardianship documents}

\author{
Joaquín Aparici Martí \\ Universitat Jaume I. Castelló \\ japarici@uji.es \\ Concepción Villanueva Morte \\ Universidad de Zaragoza* \\ convilla@unizar.es
}

Fecha de recepción: 24 de octubre de 2019

Fecha de aceptación: 31 de enero de 2021

*Profesor ayudante doctor en el Departament de Pedagogia, Didàctica de les Ciències Socials, la Llengua i la Literatura. Miembro del proyecto de investigación $\mathrm{I}+\mathrm{D}+\mathrm{i}$ de la Generalitat Valenciana (GV/2018/016) para grupos de investigación emergentes, titulado "Comercio internacional e integración económica en la Europa mediterránea y atlántica: los puertos del reino de Valencia (ss. XIII-XV)”, proyecto interuniversitario dirigido por J. Leonardo Soler (Universidad de Alicante). Es a su vez miembro de los grupos de investigación histórica FORVAL (código UJI-299/2017) y didáctica EPiCS (código UJI-300/2017). Asimismo, el presente trabajo se enmarca en el contexto de una estancia de investigación invitada en el departamento de Historia Medieval, Ciencias y Técnicas Historiográficas y Estudios Árabes e Islámicos, de la Universidad de Zaragoza (desarrollada durante el mes de julio de 2019).

** Profesora titular en el área de Historia Medieval del Departamento de Historia, perteneciente a su vez al Instituto de Investigación en Patrimonio y Humanidades. Miembro del grupo de investigación de referencia CEMA (Centro de Estudios Medievales de Aragón) (H20_17R). Trabajo desarrollado en el marco del proyecto I+D+i "Dinámicas del Estado en la Corona de Aragón en los siglos XIV-XV. Sociedad política, culturas del poder y comunicación en el reino de Aragón en una perspectiva comparada”, del Ministerio de Ciencia, Innovación y Universidades (ref. PGC2018-097683-B-100). 


\title{
Resumen
}

La infancia y la adolescencia suponen un período vital en la formación de la personalidad del individuo. Si ese período ya puede resultar duro y traumático según determinadas épocas, aún lo puede ser más si los actores del proceso son huérfanos. Presentamos aquí una contextualización sobre la vida de los huérfanos del territorio castellonense del Maestrazgo de Montesa durante la Edad Media. Para ello utilizamos los registros notariales conservados en la zona. De toda la documentación consultada hacemos especial mención a las tutelas porque ofrecen datos indiciarios sobre cómo se desarrolló la vida de esos jóvenes hasta alcanzar la mayoría de edad legal.

Palabras clave: Huérfanos; Tutela; Maestrazgo; Edad Media.

\begin{abstract}
Childhood and adolescence represent a vital period in the formation of the individual's personality. If that period can already be hard and traumatic according to certain times, it can be even more so if the actors in the process are orphans. We present here a contextualization about the life of the orphans of the Maestrazgo de Montesa in Castellon during the Middle Ages. For this we use the notarial records kept in the area. Of all the documentation consulted, we make special mention of the guardianships because they offer indicative data on how the life of these young people developed until they reached the legal age of majority.
\end{abstract}

Key words: Orphans; Tutelage; Maestrazgo; Middle Ages.

\section{INTRODUGGIÓN}

La ausencia de un sentimiento de infancia y la falta de consideración del niño como ser específico, independiente y particular durante buena parte de la Edad Media, tuvo como consecuencia su escasa presencia en las fuentes primarias. De ahí que el tema que nos atañe haya sido considerado como marginal en la historiografía tradicional, siendo abordado indirectamente desde la bibliografía sobre historia de las mujeres, o más específicamente sobre historia de la familia (Ariès, 1987; Ocón, 1995; Arroñada, 1997 y 2002; García, 1998). Dentro de estas corrientes investigadoras ha tenido bastante repercusión la visión anglosajona (Shahar, 1990; Levi y Schitt, 1996; Heywood, 2001; Orme, 2001) y también francesa (Alexandre-Bidon y Lett, 1997; Becchi y Julia, 1998) que se forjó especialmente a finales de la década de 1990 y que lo conceptualiza como un sujeto capaz de ofrecer información crucial a la hora de entender los mecanismos culturales, legales y económicos de un mundo gobernado por adultos.

Esta circunstancia de menosprecio hacia los menores hizo que a partir de los siglos XII y XIII, en el momento de renovación del Derecho canónico, se reiterase por parte de la Iglesia la condena del aborto, infanticidio y abandono de niños. Desde entonces, y a lo largo de toda la Baja Edad Media, cuando el niño/a no era deseado (fruto de relaciones extraconyugales o de amancebamiento, hijos de muchachas jóve- 
nes preñadas por sus amos...) se generaliza la adopción a otra familia o su abandono por lo general en las iglesias durante los domingos o fiestas de guardar, aprovechando la asistencia de un mayor número de fieles, o bien en las puertas del hospital durante las horas menos transitadas para evitar el juicio social. ${ }^{1}$ Si esto sucedía, se subseguían hasta tres etapas calibradas con diferentes dimensiones e impacto: la escena del abandono, el cuidado de los lactantes en manos de nodrizas y el aprendizaje en casas ajenas; realidades que generaban diversas respuestas sociales e institucionales ante esas situaciones (Boswell, 1998; Rossi, Garbellotti y Pellegrini, 2014; Rossi y Garbellotti, 2015).

El destino más corriente de su acogida eran los hospicios u orfanatos, tal como pone de manifiesto una sección del gran hospital de la Santa Creu de Barcelona (Vinyoles y González, 1982; Marino, 2019), o el de Nuestra Señora de Gracia en Zaragoza (Barquero, 1952; Royo García, 1994), ubicados en pleno corazón de la Corona de Aragón, que aparte de albergar a pobres, enfermos y locos también tenía salas destinadas a acoger a los niños abandonados en la ciudad y sus alrededores. Pero también contamos con otro ejemplo geográficamente cercano al espacio que aquí nos interesa acerca de la especialización del socorro en torno a las criaturas abandonadas registradas en el hospital de San Juan Bautista y Santa María de Villaespesa de Teruel, cuyo radio de acción, basado en una política de censales y en la colocación de huérfanos en familias, era de unos $30 \mathrm{~km}$ a la redonda (Navarro, 2000; Villagrasa, 2016).

Sin embargo, muchos de estos niños huérfanos o abandonados habían sido depositados al nacer en la institución del Padre de Huérfanos, cargo municipal encargado de encontrar colocación a menores sin padres, pero que además jugaba un papel muy importante en el acceso al trabajo de numerosos adolescentes que llegaban a la ciudad procedentes del campo o de otros lugares mucho más alejados, algunos de los cuales no eran huérfanos. Se documenta su actuación en las grandes ciudades como Zaragoza (San Vicente, 1965 y 2008), Valencia (Carreres, 1936; Rubio, 1990; Castillo 1997) y en Barcelona (Illanes, 2019). Con todo, tal vez el caso más significativo es el de Tomás Oller, un notario ciudadano de Valencia que se dedicó a tal ocupación desde 1461 hasta su muerte acontecida siete años después, con el cometido de recibir niñas y niños expósitos para que pudieran luego insertarse en la sociedad (Navarro, 1993).

El colectivo de huérfanos era muy vulnerable y sus miembros solían convertirse en víctima de las maniobras de la propia familia de sangre. Por eso, tanto en las familias de la nobleza como del patriciado urbano, lo más común era evitar que el

1 Entre la tipología de los abandonados encontramos a hijos legítimos que quedaron desatendidos y de los que se tuvieron que deshacer por la muerte de uno de sus padres (habitualmente viudas en situación de precariedad) o de ambos, vástagos ilegítimos por ser motivo de vergüenza pública (de entre ellos un alto porcentaje lo conforman los bastardos nacidos de relaciones mantenidas por los amos o sus hijos con esclavas o con mozas de servicio), por la pobreza, la prostitución o por sus defectos físicos. 
tutelaje y curaduría de éstos recayera en una sola persona para impedir el menoscabo o la pérdida del patrimonio de los herederos por una mala gestión individual. Así, en la mayoría de las ocasiones, son las justicias locales quienes nombran a un familiar directo o a otras personas de reconocido prestigio para que velen por los menores y sus bienes, siempre en consonancia con las leyes de la época que tratan de salvaguardar los intereses de los más desprotegidos. Son varios los autores que se han ocupado del estudio de las bases jurídicas y morales de esta cuestión, con carácter general en territorios de Castilla a fines de la edad media (Merchán, 1976 y García Fernández, 2019), al igual que en Portugal (De Sousa, 1980) pero también con rasgos distintivos como son las tutelas ejercidas por mujeres en Barcelona (Forns, 1997).

\section{MÉTODO A TRAVÉS DE LAS HUELLAS DOCUMENTALES SINGULARES.}

Los libros memoriales y las cartas públicas de tutela y curatela constituyen actos notariales de gran singularidad y riqueza para valorar el tema de la orfandad y sus efectos colaterales. Muestra de ello son los documentos que analizaremos en este estudio a fin de ilustrar cómo se realiza la partición de los bienes heredados por varios hermanos, qué personas se hacen cargo de las pertenencias de un familiar y cuidan de los menores y, sobre todo, cómo se arriendan dichas posesiones y se logra que los huérfanos no salgan perjudicados.

La tutela es la institución cuyo objetivo se centra en la custodia de un menor y de sus bienes porque son incapaces de gobernarse por sí mismos. Es una figura jurídica que tiene su fundamentación en el Derecho romano y que, en el reino de Valencia, por ejemplo, duraba hasta los 15 años para ambos sexos, momento en el que, en principio, la tutoría declinaba (Obarrio, 2012). Existían hasta tres tipos: testamentaria (el padre nombra en su última voluntad al tutor), legítima (se adjudicaba tutor atendiendo al parentesco, normalmente corresponde a los abuelos) y dativa (designada por la autoridad judicial en ausencia de las anteriores figuras). La tutela era, por consiguiente, la potestad concedida por el fuero a ciertas personas para que cuidasen de la persona y bienes del menor, mientras que el curador es nombrado para cuidar de los bienes y negocios del que por ausencia o incapacidad no puede administrar ni atender por sí mismo (Motis, 1992: 90). Aunque ordinariamente la curatela solía hacer referencia a los varones púberes y a las mujeres núbiles que reciben curadores desde los 12-14 años (según fuesen féminas o varones) hasta cumplir 25, porque están en una edad en que no tienen capacidad para cuidar de sus negocios. En general, el curador realiza una función tutelar restringida.

La principal obligación del tutor con respecto a los huérfanos es la alimentación y la representación judicial de los mismos, debiendo conservar y administrar rectamente los bienes de los menores y los frutos que esos bienes produzcan. El cargo de tutor era remunerado, y al término de la tutela, los bienes eran entregados de acuerdo 
con el inventario. Una vez hecha esta acción, tenía que rendir cuentas de los réditos obtenidos, de los que naturalmente era preciso descontar los gastos. Finalizada la tutela, el tutor hacía frente a los perjuicios ocasionados en el patrimonio de los huérfanos, siempre que se probase una actuación negligente.

Hecha esta breve precisión normativa, abrimos nuestra exposición haciendo alusión a la situación y al nivel de sustento de los Castrellenes, una familia acomodada de campesinos que vivía en la huerta periurbana de Valencia que, a la muerte del progenitor -a causa de la epidemia de peste de 1414-, se tradujo en la solidaridad de los parientes más próximos, quienes se ocuparon de los huérfanos. Gracias a las rigurosas cuentas que llevaron a cabo los tutores, escrituradas por el notario Joan Amalric, podemos evaluar además del paradero de los pequeños, las estrategias económicas de las élites campesinas, la importancia de los mercados y las relaciones entre el campo y la ciudad (Garcia-Oliver, 2017).

A escala más modesta, disponemos de otro ejemplo datado un 23 de abril de 1402 cuando Joan Arahuet, vecino de Villafranca -localidad del Maestrazgo castellonense, ubicada en Los Puertos de Morella-, tutor por la corte de dicho lugar asignado a las personas y bienes de Antonet y Gostança Bonet, hijos del difunto Antoni Bonet vecino de allí, empezó a hacer inventario de los bienes que correspondían a la parte de los pubiles en el reparto efectuado con su madre María Domingo, todo ello ante el notario Antoni Esquerdo. ${ }^{2}$ El inventario lo constituían bienes muebles, fundamentalmente ropas, contenedores cerámicos y útiles de cocina, valorados en conjunto en 369 sueldos 6 dineros, a los que se añadía dinero contante en cantidad de otros 120 sueldos 6 dineros. También había que sumar los 60 sueldos por quince cabezas de bestiar lanar, 15 sueldos por una arroba de lana y 20 sueldos por la parte que les correspondía de una somera (animal de carga). En total, y según hace constar Arahuet, a los dos huérfanos les correspondía un valor monetario de 525 sueldos. ${ }^{3}$ El tutor y curador manifiesta que utilizará ese montante total de la venta de los bienes en llactar, nodrir, criar e provehir los dits pubils, puesto que en el momento del óbito del padre la dita Gostança fos de temps de tres meses poch mes o menys segons dix e afferma lo dit tudor. También Arahuet indicaba que eran comunes ciertos bienes inmuebles entre la viuda y los huérfanos, a saber un alberch situado en Villafranca, un ferreginal y un huerto de tierra situado en Els Ortals, así como un trozo de tierra situado en la partida del Pimpollar del Magallo, todo ello en término del lugar. ${ }^{4}$ Como Arahuet

2 Archivo Notarial de Morella (en adelante ANM), protocolo 078 (1402, abril 23). Recientemente se ha publicado una aproximación histórica a la localidad de Villafranca durante la Edad Media (Royo, 2016).

3 Uno de los frecuentes errores que podemos encontrar en ciertos cómputos tutoriales de la época era que cuando se producía la cuadratura entre gastos y entradas, las cifras pudieran no corresponderse, como ocurre en este caso. La cifra resultante no es ni la suma de los parciales que consigna el tutor, pero tampoco la mitad que correspondería a cada una de las partes.

4 El edificio afronta con casas de Berthomeu de Lloso y casas de Miquel d'Íxer y dos calles públicas. El ferreginal y huerto afrontan con huerto y ferreginal que fue de Mateo Calba y con ferreginal y 
no estaba seguro de si había, o no, más bienes inmuebles, se retenía la posibilidad de continuar el inventario más adelante. A continuación, Arahuet consignará ante notario los gastos efectuados durante su procura y tutoría, pero paradójicamente todos éstos se concentran en un único documento. Así confirma el pago de 525 sueldos (ese total monetario que correspondía a los huérfanos) a María Domingo, la madre, per alletar, nodrir e criar los dits pubills, e per la provesió de aquells del temps ençà que son pare morí, que foren tres anys. María firma ápoca de la cantidad el 23 de abril de 1402, lo que nos indica que el óbito del padre se había producido en 1399. Pero también nos muestra que en tres años la cantidad que correspondía a los huérfanos se había finiquitado simplemente en su manutención. Y a partir de ese momento, ¿qué? ¿cuál era el futuro de los menores? ¿qué esperanza de vida tenían? ¿cuál es su devenir inmediato? Estas son sólo una parte de las numerosas cuestiones que se plantean (Navarro, 2004; Aparici y Navarro, 2010). Difícil entrada en la vida. En el caso anterior, uno era un bebé en el momento del fallecimiento del padre. Del otro no sabemos la edad, pero obviamente era menor.

En contraste con lo indicado, otros niños podían sufrir directamente el abandono. El 23 de julio de 1410 Antoni Centelles el menor, jurado de Villafranca, indicaba que a audiencia suya llegó noticia que Bernat Conesa, molinero d’en Bruscha, por sí o con ayuda de diversas personas, había llevado una criatura o fadrina la qual se dehie que ere sua, o de son germà Andreu Conesa, e aquella hagués mesa e llexada en lo spital del dit loch, requiriéndole el justicia a que fos forçat de menar-se.n la dita fadrina e que li donàs recapte e o la fes criar en manera que no.s morís n.es perdés, e ferma de dret sobre la dita demanda. Abandonada por su padre, y con la complicidad familiar, la niña quedó expuesta en el hospital, aunque en este caso el justicia actuará obligando al padre a atenderla a fin de evitar que aquella fenezca. ${ }^{5}$

Documentos relativos al Maestrazgo nos ofrecen informaciones complementarias para entender cómo era la vida de esos jóvenes, algunos de ellos huérfanos. Unimos, además, que éstos muestran a su vez la relación humana y social existente entre los habitantes a ambos lados de la vertiente montañosa del territorio, entre la zona turolense y la castellonense. El 6 de abril de 1402 Bertomeu Bonfill, vecino de Villafranca, en calidad de administrador de la limosna instituida por na Llúcia, difunta esposa del también difunto Pere Salvador, ambos vecinos del lugar, listaba ante notario el inventario de bienes asignados a dicha institución benéfica y consignados en el testamento de la finada. Sin embargo, el legado era escaso: un único alberch situado

huerto de Simó Ortí, con la Costa y con la senda, con el río en medio. Mientras el trozo del Pimpollar afronta con tierra de Jaume Cubells y tierra de Domingo Beltrán y con dicho Pimpollar.

5 ANM, protocolo 078 (1410, julio 23). Un caso un tanto diferente ocurre en 1437. Jaume Exulbí, vecino de Olocau, aldea de Morella, actuando en calidad de tutor de Domingo Exulbí, de 8 años de edad, se compromete a pagar al mayoral del Hospital dels Ignocents de Valencia los 220 sueldos que había costado la alimentación de Domingo, si bien no indica el tiempo transcurrido. Archivo de Protocolos del Real Colegio del Corpus Christi de Valencia (APRCCCV), nº 20705 (1437, diciembre 1). 
en el cercano lugar de La Iglesuela (Teruel). ${ }^{6}$ Bonfill administró ese legado durante varios años, indicando que había iniciado su actividad cuando recibió 33 sueldos de alquiler de aquella vivienda de La Iglesuela para el período que ocupaba de mayo del año 1399 a mayo de 1400, cantidad pagada por Sanxo Sanguillem (a razón de 3 florines por año). Así se mantuvo en las siguientes anualidades y precio, consignadas por Bonfill hasta mayo de $1405 .^{7}$ En total, el alquiler de la vivienda reportó unos ingresos de 198 sueldos para un período de 6 años, y Bonfill como administrador consignó les dates e distribucions fetes. Así, por orden de los jurados dio 33 sueldos a la hija de Ferrando Lópiç con el fin de pagar una capa para su matrimonio. De igual manera gastó otros 33 sueldos para vestimenta de la hija de Pere Catalá per honor de Deus en temps de ses núpcies, un cot vermell. A la hija de Pascual Juliá, por la misma razón, entregó 44 sueldos que costó una capa nupcial. También los jurados le ordenaron dar 22 sueldos a Arnau Arills, de Cantavieja (Teruel) per a obs de fer apendre son fill. $\mathrm{Al}$ año siguiente recibió Arills nuevamente 22 sueldos por la misma razón. ${ }^{8}$ Añadirá Bonfill 5 sueldos como salario del notario Antoni Esquerdo por hacer el inventario y la carta mediante la cual los jurados le encomendaron la administración, así como una cantidad indeterminada (se dejó el espacio en blanco) por dos viajes que Bonfill hizo hasta La Iglesuela per fer emperes en los bens de Sanguillem, com lo dit Sanxo fos mort e no haje pagat los loguers de les cases de la almoyna. Añadió 2 sueldos pagados al notario Esquerdo, quien por orden del consejo se había desplazado hasta La Iglesuela para recaudar los alquileres debidos.

Como vemos, las cantidades recaudadas por Bonfill pronto fueron gastadas. Pero lo relevante es observar que éstas fueron asignadas para atender las necesidades de ciertos jóvenes, en este caso no huérfanos. Algunas féminas recibieron prendas para uno de los momentos clave de su vida, como era el matrimonio. Pero también se consigna el pago de cierta cantidad durante dos años a un vecino de Cantavieja, cantidad que debía emplearse en la enseñanza y provisión de su hijo. Ahí entra otro elemento interesante relativo a la geografía y las relaciones intervecinales. La actuación del legado de la limosna concierne a poblaciones próximas, pero situadas en territorios administrativamente diferentes (La Iglesuela y Cantavieja en Teruel, reino de Aragón; Villafranca y Morella en Castellón, reino de Valencia).

6 ANM, protocolo 078 (1402, abril 6). Afronta con casas de la mujer y heredera de Bertomeu Rambla, con casas de la herrería y con casas del hospital de dicho lugar.

7 Sanguillem paga 33 sueldos por cada uno de los siguientes períodos, de mayo a mayo: 13991400 ; 1400-1401; 1401-1402; 1402-1403; 1403-1404; 1404-1405.

8 Tras la información que ofrece Bonfill, aparecen seguidamente algunos albaranes. Por ejemplo, Arills firma ápoca de la cantidad de 22 sueldos per a obs de fer aprendre e a provisió de Arnaldico fill meu, a 6 de abril de 1402. Arnau Çavall vecino de Morella confiesa recibir de Bonfill 44 sueldos precio de una capa de mujer, en fecha 8 de diciembre de 1405. Pascual Juliá vecino de Villafranca confiesa recibir de Bonfill una capa de mujer ofrecida por la limosna a su hija Maireta para su matrimonio, a 17 de octubre de 1405. 


\section{LA TUTELA DE LOS HIJOS Y BIENES DEL DIFUNTO DOMINGO MIRÓ}

Con todo, tal vez el documento que mejor ilustra la situación de los menores, huérfanos en este caso, es el siguiente. En 1403, posiblemente a finales de agosto o inicios de septiembre, fallecía Domingo Miró, vecino de Villafranca. Casado con Dolça, tras su óbito dejaba un total de cinco huérfanos menores de edad. Y por ello en fecha 6 de septiembre de dicho año la corte de Villafranca acordó nombrar a Joan Sanxo como tutor de las personas y bienes de aquellos huérfanos ${ }^{9}$ (llamados Domingo, Martí, Pere, Pascuala y María). Como buen tutor, Sanxo procedió inmediatamente a inventariar el conjunto de bienes que correspondía a dichos menores, siendo divididos mitad con mitad con Dolça, madre de los mismos. ${ }^{10}$ Sanxo llevó a término su tutela hasta el mismo momento de su propia muerte ${ }^{11}$ ocurrida en algún momento de 1411, siendo sustituido en tal tarea por Joan Blasco quien actuará en calidad de curador de Domingo Miró y tutor de Martí Miró. A partir de esos momentos, y hasta la finalización de su administración datada el 20 de marzo de 1413, ya sólo se hablará de esos dos huérfanos.

La desaparición de la progenie y la incertidumbre ante el futuro no eran situaciones inusuales para la época. Un caso similar al de los Miró lo encontramos en Segorbe. Allí los cuatro hijos del difunto tejedor Pere Martínez quedaron en 1432 bajo la tutela del también tejedor Joan Fretero. Aquellos huérfanos (llamados Bertomeu, Isabel, Teresa y Caterina) corrieron una suerte similar a los hijos de Miró. Hasta la muerte del padre, la familia Martínez había asegurado la perduración material de sus miembros y la transmisión de los valores culturales propios del colectivo donde estuvo integrada, los pequeños artesanos autónomos y con propiedades agrícolas. La dimensión de aquel grupo doméstico segorbino aparecía restringida a la pareja,

9 Quant lo pare, o la mare, hauran dexat tudor, o curador a sos fills, no ha menester confirmació de jutge. Mas no havent-hi tudor o curador testamentari, done la Cort als pubils un parent de aquells paterno lo més sufficient, sens mirar propinqüitat de grau de parentela, tan per als béns pervenguts del pare, com de la mare. O si no hi haurà paterno, sia materno, que sia major de vint anys; $y$ si no n’i haurà parents, done'ls un vehí sufficient en tudor, y axí donat, assegure detenir salvos los béns del pubil, fins aquell tinga vint anys. $Y$ en lo loch hon haurà administrat ... deu donar conte de la sua administració dins tres anys aprés que lo pubil serà fet major ... Y lo tudor que haurà mal administrat, pot ell, o sos hereus, ésser demanats per lo pubil de la mala administració (Taraçona, 1580: 178 y 181). La situación se reitera de forma contínua en territorio valenciano, como pone de manifiesto el caso de Peret, huérfano de Sueca (Guinot y Furió, 1980).

10 Com per squivar tota frau e engan, e evitar e tolre tota sospita de mal tudors e curadors en lo principi de la sua administració sien tenguts fer inventari, capbreu e memorial en scrits e ab scrivà públich dels bens dels menors, de totes e sengles rebudes e dates que faran. ANM, protocolo 078 (notario Antoni Esquerdo). El texto de la administración de esta tutela ocupa los folios $24 \mathrm{r}$ a $34 \mathrm{v}$ del manuscrito, faltando el folio 31v-32r. A partir de ahora cualquier referencia a dicha tutela se indicará en el texto con los folios entre paréntesis. El problema es que muchos de los ítems del manuscrito carecen de fecha.

11 Sabemos del óbito de Sanxo puesto que confesó in articulo mortis deber cierta cantidad de dinero a los huérfanos $(32 \mathrm{v})$. 
un bebé de entre seis y ocho meses de edad, y tres niñas menores de veinte años. Una comunidad de seis personas que, tras la muerte del padre, con la separación de bienes de la viuda, la extinción de su parte por Bertomeu e Isabel en 1434, y el óbito de Teresa antes del cierre de la tutela en 1440, sólo parece tener como único fruto de promoción social el matrimonio de la otra hija, Caterina. Fuera de la tutoría quizás la viuda contrajo unas segundas nupcias, o los niños Bertomeu e Isabel lograron superar esas altas tasas de mortalidad infantil de la época (que se habían llevado por delante a su hermana Teresa) para entrar definitivamente en la vida con un aprendizaje de oficio para él, y un servicio doméstico para ella, como le ocurrió a Caterina, de quien hemos conseguido localizar su contrato de servicio y que permite ver cómo la inexistencia de gastos sobre su alimentación y vestido en el texto de la tutela permite intuir que éstos fueron sufragados por la familia de acogida, que la alimentó y vistió, ocupándose de ella hasta llegar a la edad de maridar (Aparici y Navarro, 1996-97). De hecho, Martínez había fallecido antes del 25 de febrero de 1432, y Fretero en calidad de tutor de los herederos afirmó a Catalineta (uso del diminutivo en el original) tres meses después del óbito del padre, en mayo de ese mismo año. ${ }^{12}$

La dinámica vital seguida por los huérfanos de Miró tras la defunción de su padre fue relativamente similar a la seguida por los huérfanos segorbinos, a pesar de existir algunas diferencias de partida que pudieron afectar a su futuro. Ahora bien, los tutores de aquellos (Sanxo y Blasco) no realizaron un memorial tan extenso ni completo como el efectuado por Fretero, por lo que sólo podemos efectuar una cierta aproximación a la realidad familiar de los Miró y al incierto porvenir que se cernía sobre los huérfanos. Una de las primeras diferencias que localizamos es que el segorbino Martínez era un artesano del sector textil (tejedor) propietario de parcelas de tierra (cereal y viña). En ese sentido, el fallecido Domingo Miró intuimos que posiblemente tuvo por oficio el de pastor. Entre los bienes inmuebles que se reparten su viuda y sus hijos sólo figura una propiedad, unas casas sitas en Villafranca donde vivían y que afrontaban con las de su vecino Joan Sanxo, quien será tutor de los huérfanos (27r). No se menciona ningún tipo de parcela de cultivo (tierra, viña, çafranar o ferreginal son las que suelen aparecer en la documentación contemporánea a su óbito), si bien es cierto que Miró pudo disponer de otras formas de acceso al terrazgo, o a sus cosechas. Así, por ejemplo, Sanxo consigna entre los gastos que deben asumir los huérfanos el pago de 34 sueldos 6 dineros (mitad de los 69 sueldos) que su difunto padre había gastado en la compra de cereales al deener dels blats de Villafranca Pere Tamuç. También hace mención al pago de la parte correspondiente de otros 44 suel-

12 Caterina fue afirmada por tiempo de 6 años a servicio doméstico con el pelaire segorbino Marco Vida. Recibirá 220 sueldos al final del contrato más las ropas acostumbradas. Teniendo en cuenta que los contratos de servicio femeninos tienden a finalizar cuando las contratadas cumplen los 18 años, y que el tiempo del contrato se calcula de acuerdo a la edad que tiene la menor en el momento de la formalización del mismo, podemos suponer que si el de Caterina fue por 6 años, en el momento del óbito del padre la niña debía tener unos 12 años. El contrato en Archivo de la Catedral de Segorbe (ACS), prot. 702 / 2 (1432, mayo 20). 
dos 11 dineros por cierto forment que había comprado al morellano Jaume Morató. Pero casi más significativo que eso es la mención a otros 106 sueldos 3 dineros que el difunto debía a Morató por cierto forment que el deffunt tenia a mig guany y que había vendido (30r). Este último dato nos muestra como Miró, sin ser propietario de tierras, podía acceder a las mismas gracias a la posibilidad de cultivar alguna parcela tras llegar a un contrato de partición a medias, en el que la parcela la ponía un propietario y Miró a ús e costum de bon laurador debía cultivarla, repartiendo la cosecha según lo acordado (en este caso en mitades). En total los huérfanos debían pagar a Morató 65 sueldos 1 dinero y miaja.

Pero como decimos, sospechamos que Miró era pastor y propietario de ganados. El tutor Sanxo consignó a favor de un tal Jaume Palacio el pago de 150 sueldos que correspondía satisfacer a los huérfanos (30r). Palacio actuaba en calidad de tutor de Pascuala, hija de un tal Pere Miró, ya difunto (y tal vez familia de Domingo). Sanxo satisfizo la parte correspondiente a dichos huérfanos a pagar en aquellos 300 sueldos que Domingo Miró y su esposa Dolça confesaron deber a aquella pupila según carta pública dada en Villafranca el 28 de abril de 1396. El motivo de la deuda era por ciertas cabezas de ganado caprino. ${ }^{13}$ Además, por los bienes inventariados tras el fallecimiento de Domingo, parece corroborarse esa dedicación ganadera del difunto. En el listado se menciona una piara de cerdos formada por 2 truges (cerda de crianza), una porcella (cerdita joven) y un verraco de un año (semental porcino) $(24 \mathrm{v}, 27 \mathrm{r}$ ), animales que casi con total seguridad estarían destinados a consumo interno familiar. Pero también se mencionaba un total de 36 cabras y dos bocs (machos cabríos),

13 Localizamos el documento en ANM, protocolo no 073 (1396, abril 28) El mismo documento aparece duplicado en el notal no 103 (1396, abril 28), si bien el notal presenta además la cancelación. Según el documento, Domingo Miró y Dolça su esposa, vecinos de Villafranca, confiesan deber a Jaume Palacio como tutor de Pascuala, hija del difunto Pere Miró, 300 sueldos precio de bestiar sive armeti de cabriu que le vendió prometiendo pagarlo cuando aquella sea colocada en matrimonio, comprometiéndose a pagar 22 sueldos por año durante 4 años. El mismo día Domingo confiesa deber otros 50 sueldos precio de otros armeti, a pagar cuando ella quiera. Finalmente, Domingo confiesa tener en comanda de Palacio en dicho nombre 4 cabras y 1 cabrita que promete tener francas y sin salario o gasto, con todas las mejoras hasta que dicha Pascuala entre en matrimonio, o devolver los 300 sueldos debidos por el bestiar. Ambos documentos cancelados de voluntad de las partes en fecha 7 de septiembre de 1403 . Ya unos meses antes de las primeras noticias, el 10 de enero de 1396, Jaume Palacio actuaba como tutor de Pascualeta hija del difunto Pere Miró de un lado, ante Estefanía esposa del difunto, en la división de los bienes de aquel. Pero también la joven Pascualeta, a pesar de los bienes que podían provenir de la herencia paterna, se encontraba ya inmersa en el mundo del contrato de servicio doméstico, como tantos otros jóvenes. Así en 1395, Jaume Palacio ya la había afirmado con Arnau Serra por un período de 6 años a partir de la próxima fiesta de santa María de septiembre, alimentada, vestida y calzada según costumbre, y con una soldada de 15 sueldos por cada uno de los dos primeros años, y 30 sueldos anuales el resto del período. Por el tiempo de duración del contrato, intuimos que la joven Pascuala tenía en aquel momento unos 12 años de edad. Cuando en 1403 se cancelen las obligaciones de Domingo y Dolça, la joven ya debía haber contraído matrimonio pues dichas obligaciones se relacionaban con ese estado civil. Pascuala debía contar en esos momentos con unos 20 años de edad aproximadamente. ANM, protocolo $\mathrm{n}^{\circ} 068$ (1395, agosto 18$)$. 
tres cabrones y 12 segalls (cabritillos), a los que después se unió en el inventario la cantidad de 37 cabrones más que el difunto tenía a medias con otro vecino del lugar, y de los que la mitad corresponderían a los huérfanos (25r-v). También entre los bienes del inventario se computa a su vez la presencia de cinco squelles o cencerros para vacas o cabras (26r). Como vemos, Domingo también hizo uso de los contratos de mitgers para tener acceso a un mayor número de cabezas de ganado. Además, llama poderosamente la atención el hecho que solo aparezca en el inventario de Miró una única mención a un apero del ámbito agrario, como es una hoz o falç (26v), lo que reitera en cierta forma la sensación de escasa atención al mundo agrario por parte del matrimonio.

La idea de Miró como pastor entronca con aquello que ciertos autores clásicos ya indicaban respecto de la zona del Maestrazgo, observándola como un territorio eminentemente ganadero, como si de una tierra de pastores se tratase (Levi, 1932). Así se hablaba de una importante zona productora de lanas que eran exportadas (Melis, 1985; Rabassa, 1993); del aprovechamiento de los recursos pecuarios que la zona ofrecía, pero también de los conflictos entre poblaciones y jurisdicciones derivados del uso y disfrute de esos pastos a medida que las cabañas crecían (Sánchez, 1995; Guinot, 1992-93). Incluso se ha investigado cómo el desarrollo ganadero supuso el auge de una incipiente manufactura de paños en las poblaciones de la zona que podían aprovechar aquella materia prima local (Rabassa, 2006).

Aun así, a la actividad desarrollada por Domingo tal vez se pueda unir un complemento económico merced a las labores textiles a tiempo parcial que pudo desarrollar de forma paralela su propia esposa Dolça, quien seguramente pasaba largos períodos en casa con la única compañía de sus hijos, pues el trabajo de pastor implica muchas horas fuera del hogar (o largos períodos si se trataba de un trabajo como transhumante). Así, en aquel inventario se consignará a su vez una libra de lino, tres cuarterons de lana de menudes, unos pintes y un par de cardas, así como un peso de madera (26v). Básicamente se trata de la mención a herramientas y materia prima necesarias para las primeras fases de elaboración del producto (lino y lana), y que podía llevarse a cabo por manos femeninas no especializadas. Recordemos que, en aquellos momentos, fines del XIV e inicios del XV, Villafranca era un incipiente centro de producción de paños de calidad media. En cambio, ese listado no tiene nada que ver con los útiles que aparecían en el inventario del tejedor segorbino Martínez (que mencionaba especialmente un telar con sus arreos, unas devanadoras de pie, unos pintes para peinar lana, un ordidor de fust, y algo más de 15 libras de filaça d.estopa entre cuyta, crua e stam blanch).

Por lo que respecta a los hijos, podemos mencionar la aparente fertilidad de los progenitores que queda manifestada a través del elevado número de descendientes en el seno familiar. Como hemos indicado, los hijos del difunto Miró fueron cinco, tres varones y dos féminas. Cuatro fueron también los hijos del segorbino Martínez, 
tres niñas y un niño. ${ }^{14}$ Sin embargo, el discurrir del tiempo y las dificultades propias de la época, así como las particularidades individuales de cada uno de los huérfanos, supusieron que no todos sobrevivieran. En el caso de Martínez sabemos con certeza que una de las niñas había fallecido. Para los Miró sabemos que en diciembre de 1404 el tutor consignaba el fallecimiento de Pere y María pubils chichs e de poch temps, que moriren per les morts que eren en la terra (30v), noticia que debemos relacionar con un posible brote pestífero o mortandad generalizada que en este caso acabó con la vida de los más pequeños de los hermanos. También el 17 de octubre de 1410 el tutor consignaba ciertas entradas monetarias de Domingo y Martí indicando com les fadrines fossen mortes dies havie (28v) señalando posteriormente y en fecha indeterminada los gastos satisfechos con ocasión del entierro de aquellos tres huérfanos (31r). ${ }^{15}$ Así llegamos al 20 de marzo de 1413 cuando lo dit Domingo Miró affermant-se major de .xx. anys per si e per son germà Martí Miró, encara menor de.XX. anys de la part altra, e presents alcuns parents e amichs dels dits Domingo e Martí Miró, e ab consell de aquells, concertaron el final de la tutoría y curadoría de Blasco.

Los documentos nos permiten vislumbrar claramente las elevadas tasas de mortalidad infantil de la época. En siete años habían fallecido tres de los cinco hermanos. Sólo Domingo había alcanzado la mayoría de edad, y a partir de ese momento actuaría como tutor de su otro hermano Martí, todavía menor. En el caso de la familia Martínez, aparentemente sólo Caterina había alcanzado el objetivo y llegado a la mayoría de edad, contrayendo matrimonio y formando una nueva célula productiva. El final de la tutoría de Fretero devino 8 años después de su inicio, cuando el 3 de mayo de 1440 cobre su salario de tutor y entregue un capital de 5 libras a la dita Catalina, muller d.en Miquel de Carrión, e al dit son marit, per la part a la dita Catalina pertanyent dels damunt dits béns (Aparici y Navarro, 1996-97).

Pero la realidad de otras familias todavía era más dura. El 11 de septiembre de 1419, Pascuala, esposa de Francesc Pallarés, enferma, ordenó su testamento indicando que I fillet llur appellat Johanet, ab voler e exprès consell e consentiment de la dona na Barthomeua, mare sua, e del dit marit seu, presents, que lo dit Johanet perquè és axí

14 Aunque cada familia es un mundo y las cifras demográficas para este período son relativas y no se puede desarrollar un estudio cuantitativo acorde con la disponibilidad de fuentes, sí podemos indicar que dichas cifras atienden a factores sociales, económicos, epidémicos, cronológicos, etc... y que no resulta extraño encontrar familias con un número similar, o incluso mayor, de hijos. En 1408 Jaume Martí era tutor asignado a las personas y bienes de Perico, Miquelet, Joanet y Antoneta, sus hermanos herederos del difunto Pere Martí de Villafranca. En total, 5 hermanos. ANM, protocolo 085 (1408, julio 17). La evolución de fuegos en Villafranca durante el período en el que vivieron nuestros protagonistas es la siguiente: 1373 (209 fuegos), 1385 (202), 1397 (133), 1414 (70), 1427 (108) y 1430 (103). El lugar queda integrado en la dinámica general del momento, con la progresiva reducción de su capacidad demográfica desde fines del siglo XIV hasta la década de los 20 del siglo XV, reduciéndose el volumen poblacional del orden del 50\% (Guinot, 1988).

15 Ítem dix que havie despés e pagat a les messions de les sepultures dels dits Pere, Pasquala e Maria, pubills, entre los moretoris, novenes, cera e oblades, e lenç per a les mortalles, per tot, ... .xxxi. sous, .x. diners (31r). 
petit e molt flach, sie e romangue a regiment de la dita mare sua per spay de I any contador après opte seu. Viendo próximo el final de sus días, y observando la debilidad de su hijo (muy pequeño y delgado), ordenó que la abuela se asegurara, al menos durante un año, de su manutención. Para ello asignó dos cahices de forment y dos florines de oro para mantener a Joanet. Y a la abuela materna Bertomeua le asigna, por sus trabajos de tenir cura del fadrí, los ropajes y joyas de casa. El testamento se publicó el día 20 de septiembre. Sin embargo, transcurrido aquel año, y en fecha 21 de octubre de 1420, na Bertomeua viuda de Mateu Malgrat, abuela de Joanet; y el padre de éste, Francesc Pallerés, vecino de Cinctorres, llegaron a un nuevo acuerdo según el cual ella se comprometía a que alimente e nodresque e proveesque de boqua a Johanet Pallarés, de ací a la festa de sent Miquel del mes de setembre primervinent. Joanet había sobrevivido al primer año sin madre. Ahora se enfrentaba a un segundo año, estando nuevamente al cargo su abuela materna. El padre, Francesc, se comprometerá a proveer a su hijo con otros 2 cahices de forment y dos florines de oro. Pero este acto ante notario presenta a continuación un añadido donde se pone de manifiesto que com lo dit Johanet morís a poch estar, per ço les dites parts manaren la present carta ésser cancellada. ${ }^{16}$ Joanet no había sobrevivido ese segundo año.

Precisamente, esa es una de las dinámicas demográficas valencianas del momento. El estancamiento demográfico tenía una de sus causas en la reducción del número de hijos supervivientes por cada familia. Con independencia a la progenie aportada, solo uno o dos hijos por matrimonio llegaban a suceder a los padres en la herencia de las propiedades familiares, lo que muestra una tasa de reproducción mínima, que apenas aseguraba la renovación generacional. Por ejemplo, el estudio de ochenta y tres testamentos del área de Alzira entre 1369-1523 muestra que el 47\% de las familias no tenían descendencia; un 26,5\% solo tenían un hijo; el 19,3\% tenía dos hijos; y el restante 7,2\% variaba entre tres y seis hijos (Furió, 1990). Con todo, el aprovechamiento demográfico de cifras y datos a partir de fuentes no demográficas ni seriadas debe realizarse siempre con cautela.

La situación en la que se encontrarán los hijos de Miró tras el fallecimiento del padre parece confirmar el mismo mecanismo socio-económico que se detectaba en Segorbe. Como hemos indicado, se produce una inicial división de bienes. El valor de los bienes inventariados el 7 de septiembre de 1403 (fundamentalmente ropaje y enseres de cocina, algunos de ellos considerados como de poco valor) ascendía, según el tutor, a un total de 208 sueldos 10 dineros ${ }^{17}$, bienes vendidos a na Dolça, madre de los

16 ANM, prot. 159 (1419, setembre 11); prot. 159 (1420, octubre 1).

17 El texto de un inventario puede recoger las nomenclaturas de los objetos, en ocasiones su descripción detallada, e incluso también indicar su disposición u ordenación en el espacio habitado. Este mundo de los objetos bajomedievales es el que permite acercarnos a la imagen más íntima que tenemos de la vida y las posesiones de las gentes, más incluso que la arqueología. Pero en conjunto, y para la inmensa mayoría de inventarios, se nos muestra más la austeridad del mobiliario con interiores sin grandes atractivos ni elementos de lujo. Tan sólo cuentan los conjuntos, con la percepción de una atmósfera general que es sobre todo de trabajo y esfuerzo, de supervivencia más que de confort y ocio, 
huérfanos. La indicada cantidad se destinará a la alimentación, vestido y calzado de todos aquellos por parte de la misma madre, ya desde el mismo día 6 de septiembre, con cierta asignación de cereales, companagium, y dinero para vestidos y calzados. ${ }^{18}$

aunque a veces exista. El presente inventario de bienes de Domingo Miró se corresponde únicamente con la parte que pervino a los huérfanos, es decir, la mitad del conjunto. En él podemos observar esa cierta austeridad y atmósfera definitoria. (25v) Posthea vero die veneris .VII. mensis septembris anno predicto a Nativitate Domini M $^{\circ} \mathrm{CCCC}^{\circ}$. tertio, lo dit en Johan Sanxo tudor qui dessús continuan un inventari, rebé com a bens dels dits pubills les coses e bens infrasegüents, los quals per sort vingueren a part dels dits pubills en la partició que.s fahie entre lo dit tudor en nom dels dits pubills de una part, e la dona na Dolça mare de aquells de la part altra, la qual havie fet, e feu sagrament en poder de la cort del dit loch, que bé e leyalment adurie a partició ço és los bens comuns entre ella e lo dit deffunt: Primo una capa de sayal bona, nova ... .XV. sous. Ítem altra capa de sayal oldana ... . . . sous. Ittem quatre alnes e miga de drap blau ... .XXVII. sous. Item dos parells de calces oldanes, regen ... .I. sou. Ítem una capa de burell, regen, oldana ... .III. sous. (26r) Ítem una capa de burell morenisch fort curta ... .v. sous. Ítem un fasset blau de hom ... .v. sous. Ítem una tocardia blava del dit deffunt ... . viII. sous. İtem quatre gonelles totes squexades ... .II. sous. Ítem dues lances, una bona, altra sotil trenquada, e.IIII. darts ... .XII. sous. Ítem miga flaçada oldana, regen, $e$ de poqua valor ... .vI. diners. Ítem dos capçals serraneschs ab ploma ... .v. sous. Ítem un manil o cortina oldana ... .IIII. sous. İtem una cuberta de plomaça ... . viII. sous. Ítem un llançol de llana oldà ... .II. sous, .VI. diners. Ítem .XV. scudelles e quatre talladors ... .III. sous. İtem un cabaç de palma, regen ... .IIII. sous. Ítem un troç de llançol de lli oldà, regen ... .IIII. diners. Ítem tres tovalles, les dues regen oldanes de alna e miga ... . v. sous. İtem un coltell marraça e una destral ... .VI. sous. Ítem tres peces de obra de terra ... .VI. diners. Ítem una canasta, un covaniello, un canastell, una cistella, .I. panisereta, tot oldà e de poqua valor .... .IX. diners. Item una hanziella e un tallador oldans ... .VI. diners. Item cinch squelles regen oldanes ... .VII. sous, .VI. diners. (26v) İtem un arquibanch e un banch tot de pi .... .VIII. sous. İtem una lliura de lli en çerro ... .vI. diners. Îtem un banquet ... .III. diners. Ítem tres quarterons de llana de menudes ... .v. sous, .III. diners. Ítem un llit de cordes ab sa màrfega de poqua valor ... .I. sou. Ítem un troç de sobrellit de poqua valor ... .II. diners. Ítem un cofret oldà regen ... .III. sous. Ittem una ferrada, dues cubes e tres gamelles tot oldà .... .v. sous. Ítem una caldereta e uns pintes, un moro e dos parells de cardes, tot oldà regen ... .VI. sous, .VI. diners. Ítem quatre alloces, una rasera, una falç, un pes de fust, oldans ... .IIII. sous. Ítem una tauleta de mengar, un banch senyer, tres banques.... .IIII. sous. Item dos cabeçalegos, un saler de fust, un contador, una gamelleta, oldans ... .VII. sous. Ítem quatre talleques oldanes ... .VI. sous. İtem un sedaç tot oldà, un terraç e altres menuderies de poqua valor ... . viII. diners. Ítem una cuna oldana regen ... .viII. diners. (27r) Ítem la meytat per indivís de dues truges e de una porcella e un verraquo de un any ... .xxv. sous. Item dues olles oldanes ... .IIII. diners. Ítem la meytat per indivís de una pastera e d.un capell obrat squexat, e de una sàvena e de una bossa antiga de dona, e de una orça e de dos banquets ... .v. sous. Los quals dits bens mobles e per si movents stimats per en Johan Gómiç e Domingo Mas, vehïns de Vilafrancha, los quals havien fet sagrament en poder de la cort del dit loch sobre los sants quatre evangelis de ses mans dretes corporalment toquats que bé e leyalment stimarien e aprearien aquells, los quals stimaren segons les stimes dessús scrites e de fora treytes, foren venuts per lo dit tudor a la dona na Dolça, mare dels dits pubils per a obs e necesitat de provehir aquells de mengar e beure, vestir e calçar majorment, per los preus e estimes dessús scrites e de fora treytes, que munten en suma e quantitat de doents huyt sous, deu diners, ab.XI. sous que la dita dona havie a tornar als dits pubils per tornes de la dita partició. La suma real es de 210 sueldos 11 dineros

18 Ítem dix que havie dat a la dita dona na Dolça mare dels dits pubills per provesió de aquells del .vi. én dia de setembre del any de la Nativitat de nostre senyor.MCCCC. e tres, tro al .XXI. dia del mes de agost del any aprés següent per composició e avinença feta entre ell el dit nom e la dita dona. Ítem dix que havie dat a la dita dona per provesió dels dits Pere e Maria pubils chichs e de poch temps, del .xxI. dia de agost del any de la Nativitat de nostre senyor.MCCCC. e quatre tro al mes de dehembre que moriren per les morts que eren en la terra, com los ne fos tatxat per inventari tres kafiços.I. faneca de forment, e vint sous de companatge, e.XXV. sous per vestir e calçar, venie-lin per tres meses que visqueren, ... .XXXV. sous (30 v). 
Aquel mismo 7 de septiembre el tutor Joan Sanxo procedió a la venta del ganado ante la necesidad de pagar las deudas del difunto, procediendo a subasta pública de los mismos a través del sayón y corredor del lugar Francesc Nicolau. Andreu Serra, vecino de Villafranca ${ }^{19}$ compró 28 cabras y dos bocs a razón de 5 sueldos 3 dineros por cabeza, ascendiendo el total a 157 sueldos 6 dineros. Le vendió también ocho segallas (cabritillas) a 3 sueldos por cabeza, sumando 24 sueldos. Al carnicero del lugar, García Ortí, le vendió siete segallas y dos primals de cabra del rebuig (cabras entre 1 y 3 años) a razón de 5 sueldos por cabeza, que sumaron 45 sueldos. También a Pere Ferrándiç, vecino de Chiva de Morella, 4 cabras y la mitad por indiviso de una quinta cabra, a razón de 3 sueldos 6 dineros por cabeza, sumando 15 sueldos 9 dineros. El total del ganado vendido en esa fecha ascendió a 242 sueldos 3 dineros. El tutor continuó la venta de bienes de los huérfanos el 6 de agosto del año siguiente, 1404.

Ese año nuevamente menciona la venta de animales, tres cabras y media a Pere Ferrándiç por un montante de 17 sueldos 6 dineros; un choto joven (cabritillo, carnero o corderito lactante) a Guardiola por 5 sueldos. Y también consignará que había recibido de la venta de los cabrones que tenía el difunto a medias con Joan Vinesques un total de 34 sueldos y 5 dineros que son la parte correspondiente a los huérfanos. Añadirá a su vez otros 20 sueldos que correspondían a los huérfanos y que adeudaba Francesc Chiva de una venta de cabras que el difunto le había hecho en vida (28v).

A pesar de la monetarización de los bienes para suplir las necesidades de los menores, los huérfanos más pequeños (Pere y María) habían fallecido rápidamente, apenas dieciséis meses después que su padre. La tutela sobre ellos finalizaba, pues, en diciembre de 1404 centrándose en el resto de hermanos, aunque sabemos que pronto murió también Pascuala. Pero había que ocuparse de los supervivientes. Sobre Martí ciertamente no se consignan informaciones salvo que, al final, quedará tutelado por su propio hermano Domingo. No obstante, respecto a Domingo sí podemos esbozar cómo debieron ser sus años de adolescencia, vinculados al trabajo dentro del ámbito ganadero, posiblemente a imitación de su padre.

\section{EL FUTURO DE LOS HIJOS}

En ese sentido, y en relación al hijo mayor, el tutor menciona el 17 de octubre de 1410 un contrato o affermament de Domingo para cuidar cierta cabaña ganadera no especificada. Pero a continuación el tutor pasa a enumerar todos los contratos anteriores de Domingo, mostrándonos que rápidamente tras el óbito del padre, este joven huérfano entró en el mundo laboral, situación similar a la de Caterina, la hija de Mar-

19 Andreu Serra, de Villafranca, era yerno de Jaume Palacio, pues estaba casado en germanía con Estefanía, hija de aquel. Pocos días después la otra hija de Palacio, María, se casaba con Gil de Cabriella, también de Villafranca. Recordemos que Palacio estaba relacionado con los Miró a través de su tutela sobre Pascuala. ANM, protocolo no 73 (1396, enero 17 y abril 29). 
tínez, y a la de otros muchos niños. ${ }^{20}$ Entre 1406-1407 y 1407-1408 Domingo estuvo contratado con Domingo Beltrán, son padastre (28v), por un total de 21 meses, con salario anual de 35 sueldos (recibiendo en total 56 sueldos 3 dineros). Esa información nos muestra de forma paralela las amplias posibilidades de contraer segundas nupcias por parte de las viudas relativamente jóvenes y con recursos, como debía ser la madre de Domingo, joven que a su vez recibía una nueva figura paterna de referencia. Domingo también fue afirmado entre 1408-1409 con Bertomeu Tamuç, de Villafranca, para guardar el bestiar, con un salario de 35 sueldos. ${ }^{21}$ A continuación el tutor consigna la entrada de otros 35 sueldos por un año más desarrollando el mismo oficio, entre 1409-1410, pero ahora con Guiamó Tamuç (29r). ${ }^{22}$ Todavía en 1411 el nuevo tutor, Blasco, dix que havie comprat cuyro de bou per a calcer a Domingo Miró, qui stà ab Domingo Just a pastor, lo qual costà .VI. sous .IX. diners (34r), noticia que corrobora la continuidad de Domingo en el trabajo como pastor.

$\mathrm{Y}$ es que, aunque no hayamos localizado contratos de afermament de pastor redactados ante notario en el ámbito de Villafranca, da la sensación de que éstos sí

20 Por ejemplo, Domingo Alberit era en 1421 tutor de las personas y bienes de los huérfanos de Bertomeu Badenes, que estaba casado con Dolceta. El documento muestra nuevamente una abundante prole, formada por cinco hijos: Pascualica, María, Dolcina, Alicsén y Bertomeu. Tras hacer el inventario de bienes para dividir entre madre y huérfanos, avingueren-se ab Dolceta de lactar lo fadrí a XI sous per mes a un any que comença prima present mensis aprilis. Ítem per la pubilla Alichsén per un any, XVI sous ab la precepta etc... comptan prorata temporis ... la podia afermar. Aparentemente Alberit se aviene con Dolceta sobre los más pequeños de los huérfanos, que ella nodrís e criàs lo dit Berthomeu Badenes e la dita Alichsén per un any següent per los dits CLXXXVIII sous, e que aquells se paguen dels béns comuns del dit pubil e pubilles. Pero además se mencionaba a su vez la posibilidad de concertar un contrato de afermament para Elicsén. Del resto de hermanos no se indica nada más. ANM protocolo no 095 (1421, abril 10). Como vemos, la dinámica de los contratos de aprendizaje y servicio en la zona era bastante común (Aparici y Rabassa, 2019). En esa investigación se registraron hasta 164 contratos de aprendizaje o servicio doméstico redactados ante notario para un período que ocupa desde 1310 a 1511 si bien en ninguno de esos contatos se mencionaba a nuestros protagonistas. El servicio doméstico (54 contratos) y el sector de la tejeduría y sastrería (15 contratos cada uno) o la zapatería (14 contratos) son los más documentados. Curiosamente, en una tierra de dedicación ganadera sólo se documentaba un contrato de pastor. Un joven de Villafranca llamado Peret fue afirmado el 21 de septiembre de 1449 por su padre Domingo Tena como pastor de Joan Estrader, a pastoregar e o altres llícites e honestes fahenes, por tiempo de cinco años alimentado, calzado y vestido según costumbre, y una inusitada paga final de 300 sueldos.

21 Durante ese período, el tutor consigna un gasto relativo a indumentaria: Ítem dix que havie despés en una gonella que.l dit tudor comprà per al dit Domingo, d.en Apparici Ivanyes l-any que lo dit pubill stave ab Berthomeu Tamuç affermat que ere l.any de la Nativitat de nostre senyor .MCCCCVIII ${ }^{\circ}$. que finí en .IX $X^{\circ}$., ... .XI. sous (31r).

22 Domingo Beltrán, padastro de Domingo, se dedicaba al mundo ganadero. En 1417 sabemos que vendió a Bertomeu Munterde, de Villafranca, 20 arrobas de lana y añinos a razón de 13 sueldos la arroba, recibiendo en señal 20 florines. Canceló el contrato de mutuo acuerdo el 26 julio 1417. Guiamó Tamuç también se dedicaba al mundo del ganado. En 1405 Antoni Centelles el menor de Villafranca donó a Guiamó Tamuç 105 ovejas y 2 cabras a medias por 5 años a contar desde el próximo día de san Miquel, partiendo borregos machos, lana y añinos. En 1409 Domingo Alberit de Villafranca confesó deber a Guiamó Tamuç 70 sueldos precio de armenti. ANM, protocolo no 080 (1405, diciembre 1); $\mathrm{n}^{\circ}$ 087 (1409, diciembre 29); nº 090 (1417, julio 12). 
existían como queda referenciado a través del caso de Domingo Miró. Y como el suyo, también se documenta otro que resulta muy interesante. En ese sentido, una de las noticias más antiguas que conocemos al respecto en la zona de estudio corresponde al joven Joan Mauri, quien fue acusado de practicar la herejía del catarismo. Su confesión ante el inquisidor del convento de Lleida en junio de 1323 mostraba toda una adolescencia dedicada al mundo ganadero, similar a Domingo. Según su relato, en el período 1310-1311, con una edad aproximada de 13-14 años, llegó al Maestrazgo procedente de Montalió (Occitania, sur de Francia). El yerno de su tío materno, Guillem Esteve, lo contrató como pastor con Jaume de Capcir, de Vilafranca de Conflent (Cataluña), con quien estuvo un período de dos años. Con las ovejas de aquel indica que iba y venía hasta Capcir. Pasados esos dos años (1312-1313), y con unos 15-16 años de edad, se contrató con Pere Lileto, de Puigcerdà (Cataluña), con quien estuvo unos tres años. Indica que conducía el ganado de Lileto hasta La Granadella (población de Lleida), acompañado por otro pastor llamado Pere Cortill. Transcurridos esos tres años, y aproximadamente con unos 18-19 (mayoría de edad), retornó a su tierra natal, a Montalió, pero por una serie de problemas con otros pastores decidió regresar a territorio catalán. En Puigcerdà se contrató como pastor de la cabaña de Ramón Bosser y de su esposa Bruniscenda de Cervelló, por un período de unos cuatro años. Durante ese período dijo recordar que llevaba las ovejas desde Castelldases (Lleida), junto a otros pastores, hacia la plana de la Sènia próxima a Tortosa, desde donde retornaba después hacia las montañas de Morella, y a través de Beceite (Teruel) se dirigía nuevamente a Castelldases. Incluso menciona que antes de ese contrato estuvo cierto tiempo en un lugar llamado Bagano, en las montañas, con el ganado de un tal Pere Dezcastell. Joan retoma su relato y vuelve a mencionar que pasados esos cuatro años (1319-1320 aproximadamente, y con unos 22-23 años de edad) se dirigió hacia el Puerto de Isábena, donde trabajaría como pastor de Ramón Calder. Sin embargo, problemas de bandosidades entre nobles le harán retornar hacia la actual provincia de Castellón, vía Ulldecona, para residir en San Mateo (Maestrazgo castellonense), donde convivió con una hereje. Finalmente indica que, en el momento de su captura y confesión (junio de 1323, contando con unos 26-27 años aproximadamente), estaba contratado como pastor de Pere Robicau, vecino de San Mateo, por un período que finalizaba en septiembre de ese mismo año. Ciertamente pastor, y como el propio Mauri declara, conduciendo ganados por las montañas, de forma continua, a veces solo y otras en compañía. Mauri confesará que conversaba con aquellos otros pastores sobre sus creencias. Toda una adolescencia dedicada al ganado (Grau, Berga y Cingolani, 2015: doc. 269).

Retomando la figura de Domingo Miró, a pesar de las ventas de ganado que había efectuado años antes el tutor Sanxo, y a pesar de trabajar contratado como pastor cuidando la cabaña de su padastro, de los Tamuç o de Just, el propio Domingo debía poseer algunos animales en propiedad. De hecho, el tutor Sanxo consigna en el memorial la entrada en 1409 de 36 sueldos por la venta de 2 arrobas de lana (a 18 sueldos cada una) procedentes del bestiaret del dit Domingo. En 1410 consignó la entrada de 
38 sueldos por la venta de otras 2 arrobas de lana (vendidas a 19 sueldos cada una). El uso del diminutivo en el original en referencia a la cabaña ganadera parece implicar la propiedad de un reducido número de cabezas. Así, si atendemos a que para obtener una arroba de lana se precisa de, aproximadamente, unas 6 ovejas, ello supondría que Domingo era propietario de unas 12 ovejas. Tal vez esa cabaña ganadera pastaba de forma conjunta con la de los propietarios para los que trabajaba como contratado. Pero un nuevo dato nos permite descubrir de dónde posiblemente provenían las reses de Domingo. El 29 de octubre de 1411 el tutor Blasco procedió a anotar nuevamente en el memorial de la tutela algunas entradas a favor de Domingo. En una de ellas no especificaba cantidad monetaria alguna pero sí que disponía de cierta lana del bestiaret de Domingo (una arroba y 15 libras), añinos (16 libras), cerpas de lana (13 libras), cantidades similares a los años anteriores. Pero aquello diferente es que también anotaba el pago de la soldada de Domingo efectuado por Guiamó Tamuç. Ese pago se había efectuado en especie consignándose un total de nou caps de bestiar que ampliarían el conjunto de reses propiedad del joven Domingo (33v). Tal vez el conjunto de su cabaña era el resultado de los pagos en especie por su trabajo como pastor, y no procedían de la herencia paterna. ${ }^{23}$

Por otro lado, Domingo era joven y había sido contratado como pastor. Con esa edad pudo llegar a cometer algunos errores de juventud, caso de ciertas gamberradas; o también ciertos descuidos en el cuidado del ganado o la piara de cerdos, que en ocasiones provocaban daños en cultivos ajenos. Ambos aspectos supusieron el pago de ciertas composiciones de las que el tutor Blasco dejó constancia. ${ }^{24}$

A pesar de todo, al final la tutela ofrecía un saldo económico positivo a favor de los dos huérfanos supervivientes. Joan Sanxo murió en 1411 y según se muestra en la contabilidad del memorial (32v) la relación entre los ingresos (723 sueldos 4 dineros) y los gastos ( 605 sueldos 6 dineros, mealla) durante su período tutelar arrojó un valor en positivo de 117 sueldos 9 dineros, mealla, a los que se añadían otros 22 sueldos que Sanxo había olvidado contabilizar y que confesó deber a los huérfanos in articulo

23 En otra anotación el mismo Blasco indica que las cabezas de ganado servían para cubrir la deuda monetaria del salario no satisfecha: Ítem dona segons dix a Guiamó Tamuç per tornes de una segalla que prés en ses pagues ab d.altre bestiar, dels.xL. sous de soldada que devie a Domingo, ... .vi. diners. Ittem dix que havie treballat un dia en recaptar e haver la dita soldada del dit Guiamó Tamuç (34r). Tal vez la anotación muestra un pago en moneda de 40 sueldos que no se satisfizo, cobrándolo por tanto en especie, y restituyendo 6 dineros por exceso de valor de las cabezas entregadas. Además, el tutor indica que estuvo un día para poder cobrar dicha soldada.

24 Item dix que havie pagades de talles que havie fetes lo dit Domingo, com se hagués appar ell a la meytat, com muntassen .XVIII. sous, paga lo dit tudor per lo dit Domingo, ... .IX. sous. Item lo dit any lo dit Domingo talla un plantó de cirer, el ferreginal de $n \cdot$ Anthoni Mir, costa per avinença, ... .I. sou. Ítem lo dit Domingo tragué guinxes lo dit any del ferreginal de Miquel Sala, havie comés de pena.x. sous, costa per avinença, ... II. sous. İtem paga l.any que stave lo dit Domingo ab son padrastre per tales que feu ab los porchs, ...... sous (31r). 
mortis según referenciaba el rector y vicario del lugar Bertomeu Gardull. ${ }^{25}$ Así pues, el total que recibieron los dos huérfanos supervivientes tras el óbito de su primer tutor ascendió a 139 sueldos, 9 dineros, mealla ${ }^{26}$ cantidad que pasaba a manos de Joan Blasco que actuará en nombre de curador de Domingo Miró y tutor de Martí Miró. Blasco reconocerá haber recibido esa cantidad procedente de los herederos del anterior tutor y continuará con el memorial. ${ }^{27}$ Aún con todo, Blasco consignará un pago por cuanto tuvo que citar a la difunta esposa de Sanxo, n'Altadona, a fin de que ésta satisficiera la cantidad que por su parte se adeudaba a los huérfanos. ${ }^{28}$

El memorial incluye también nota relativa a otros gastos derivados de la misma, sin fecha que nos permita una reconstrucción cronológica, como el pago por la redacción del inventario y otras escrituras al notario Antoni Esquerdo ${ }^{29}$; el coste por la sepultura del padre de los huérfanos ${ }^{30}$; el pago de Blasco a Antoni Esquerdo por la pecha adeudada por los huérfanos ${ }^{31}$; o la retribución al notario Jaume Roig por los escritos en que Blasco era designado como tutor ${ }^{32}$.

La última anotación fechada el 20 de marzo de 1413 pone fin a la administración de Blasco. Ésta se cancela a petición de Domingo Miró, quien declara ser mayor

25 Los testigos de lo que referenciaba el rector fueron el propio Joan Blasco por un lado, y Simó Ortí y Pascual Sanxo por el otro (32v).

26 Perqué fou vist que restave que havien a cobrar los dits fadrins per los dits bens mobles del dit en Johan Sanxo e de sos hereus ab los dits .XXII. sous, ... .CXXXIX. sous, .IX. diners, mealla (33r).

27 Los quals dits .CXXXIX. sous.IX. diners mealla, lo dit en Johan Blasquo el dit nom de curador del dit Domingo Miró e tudor del dit Martí Miró, confessa haver rebut dels dits hereus d.en Johan Sanxo en la manera deiús scrita, ço és que en Domingo Beltran vehí del dit loch entre ditor e plan pagador al dit en Johan Blasquo el dits noms, de cent e vint e sis sous de la dita moneda reals de València per los dits hereus del dit en Johan Sanxo; e la dona n.Altadona muller quondam del dit en Johan Sanxo li entre ditora e plana pagadora per los dits hereus dels.XIII. sous.IX. diners mealla restants a compliment dels dits.CXXXIX. sous .IX. diners mealla. En aprés que los dits hereus d.en Johan Sanxo és vist que han pagat tot ço que devien per los dits bens mobles segons lo dit inventari e finaments de comptes dessús dits als dits pubils fills d.en Domingo Miró. Protesta ut infra fiat hic. Presents testimonis foren a les dites coses los discrets en Galceran Yenegueç rector de la Serra d.en Galceran e Berthomeu Gardull, preveres habitants en Vilafrancha (33r).

28 Ittem dix que despés en citar e fer condepnar a n.Altadona dels.XIII. sous.IX. diners mealla que li devie o li ere entrada ditora per en Johan Sanxo quondam tudor dels dits pubills, e citar a Bux per rahón de una barata que havie feta ab lo dit Domingo a dan seu, ... .IIII. diners (34r). El tutor Joan Sanxo había contraído matrimonio según el formato de la germanía con n’Altadona en el año 1405, es decir, en plena tutoría. ANM protocolo no 081 (1405, junio 15).

29 Item dix que havie donats a Anthoni Esquerdo notari per les scriptures del present inventari e per [ordenar] dues cartes en les quals lo dit deffunt ere obligat a Jacme Palacio com a tudor de la filla de Pere Miró, e per cancelar aquelles e per ordenar la requesta de la sua tutela, per tot ... .X. sous (30v).

30 Ítem dix que havie despés e pagat a les messions de la sepultura del dit en Domingo Miró deffunt altre [...] moretori, novena, aniversaris, un altre jorn, altre al .IX. jorn, altre al cap del any, oblades, çera e lenç de la mortalla, per tot, .... .xxxIx. sous, .x. diners (31r).

31 Item dix que havie pagat a Anthoni Esquerdo peyter del dit loch per mitja lliura de molta dels dits pubills per l-any .MCCCCXI., ... .II. sous, .IX. diners (34r).

32 Ittem dix que havie dats e pagats a.n Jacme Roig notari per scriptures de la assignació feta per la cort de ell a tudor, ... .III. sous (34r). 
de 20 años. Lo hace por él mismo y por su hermano Martí, todavía menor. Ajustada la contabilidad durante el período tutorial de Joan Blasco, éste debía reintegrar a los huérfanos un saldo positivo de 152 sueldos. ${ }^{33}$ Sin embargo, a partir de ese momento, se pierde toda referencia documental a ambos hermanos. ¿Contraería matrimonio Domingo? ¿Sería afirmado para aprender un oficio Martí? ¿Quedarían ambos hermanos viviendo en Villafranca, o buscarían fortuna en otras poblaciones?

\section{CONCLUSIONES}

La tutela es una institución jurídica de larga tradición histórica. Los documentos de tutela que han sido analizados nos hablan de niños/as huérfanos o abandonados como algo que formaba parte integrante del paisaje cotidiano de la realidad social de esa época. La institucionalización o no de estas criaturas es un debate que ya se planteaba en la Edad Media y que a día de hoy aún continúa vigente, entrando en juego la asunción por el Estado de la responsabilidad en materia de protección de menores en situación de desamparo.

Según los testimonios que se han ido recuperando, posiblemente aquellos pequeños desfavorecidos vivían en una situación de marginación ya desde su llegada al mundo; ya fuera por su situación de abandono, por carecer de las condiciones mínimas de subsistencia como la alimentación y la vestimenta, o bien por verse expuestos ante el cuidado de desconocidos y a una constante circulación que les impedía establecer lazos afectivos con sus cuidadores. Con todo ello podemos hacernos una idea de lo difícil que pudo ser para estos pupilos/as establecer relaciones de confianza y sociabilidad con las personas de su entorno.

Estudiamos, en definitiva, los indicios de creación de dichos lazos afectivos entre las criaturas y las familias que les acogen, y cómo puede repercutir el trato que reciben en sus posibilidades de integración social. Teniendo en cuenta esta premisa, una cuestión prioritaria sobre la que se ha intentado indagar es si esos niños/as y jóvenes compartían las expectativas y el futuro que en ellos ponían. Y, paralelamente, otro asunto sobre el que se ha procurado explorar es el de la inversión social o sociológica de las familias para con ellos durante un tiempo vital en el que se constatan apreciaciones ambiguas y ambivalentes.

33 Posthea vero die lune, .xx. marcii anno a Nativitate Domini . $^{\circ}$ CCCC $^{\circ}$ XIII ${ }^{\circ}$. En lo loch de Vilafrancha en presència de mi Anthoni Esquerdo notari et dels testimonis deiús scrits, constituits personalment lo dit en Johan Blasquo als dits noms de una part, e lo dit Domingo Miró affermant-se major de .XX. anys per si e per son germà Martí Miró, encara menor de.Xx. anys de la part altra, e presents alcuns parents $e$ amichs dels dits Domingo e Martí Miró, e ab consell de aquells, vingueren a conte sobre los dits bens, rehebudes e dates en lo present inventari contegudes. Et sumades rebudes e dates per ell dit Johan Blasquo fetes e abatudes dates, e.II. sous.II. diners que li foren rehebuts en compte de dates per sos trebals de regir los dits bens, fon vist per compte finat que havie a tornar lo dit Johan Blasquo de la dita administració ço és \cent cinquanta-dos/ sous moneda reals de València. Presents testimonis foren a les dites coses Domingo Alberit e Bernat Ayoro, vehïns de Vilafrancha (34v). 
Para terminar, cabe señalar que todo este panorama descrito se transformará desde finales del siglo XV e inicios del XVI, cuando se inicie un proceso en el que esa conciencia de un ciclo de vida circular dé paso gradualmente a una idea más lineal y segmentada de la existencia. Esa mutación cultural, en la que el individuo y lo privado se van abriendo camino, se traduce en una nueva sensibilidad en la que la familia ya no era solo una unidad económica o un lugar de obligaciones y coacciones para sus miembros, sino que tendió a convertirse en un espacio de cariño y de afectividad en el que la naturaleza propia y peculiar de la infancia se hizo visible y se diferenció progresivamente del universo de los adultos. Una prueba fehaciente de este cambio es que a principios del Quinientos encontramos los contratos de «afillament» (ahijamiento $)^{34}$ que ya podemos identificar como verdaderas adopciones legales.

\section{BIBLIOGRAFÍA}

Alexandre-Bidon, Daniel y Lett, Didier (1997). Les enfants au Moyen Âge, $V^{e}$-XVesiècle. París: Hachette.

Aparici Martí, Joaquín y Navarro Espinach, Germán (1996-97). El libro memorial de la tutela del tejedor Joan Fretero (Segorbe, 1432-1440). Estudis Castellonencs, 7. Diputació de Castelló, pp. 231-264; y más recientemente (2019), La herencia de un tejedor valenciano en el siglo XV. Nueva edición del manuscrito de Segorbe. Aragón en la Edad Media, 30, pp. 243-293.

Aparici Martí, Joaquín y Navarro Espinach, Germán (2010). Considerada encara la pocha edat e ignocència ... los primeros años de vida para los niños del siglo XV. Millars, Espai i Història, 33. Castelló, Universitat Jaume I, pp. 55-74.

Aparici Martí, Joaquín y Rabassa Vaquer, Carles (2019). Ensenyar i aprendre. La formació professional a través dels contractes d'afermament dels segles XIV i XV al Maestrat i Els Ports de Morella (Castelló). Millars, Espai i Història, 46. Castelló, Universitat Jaume I, pp. 73-113.

Ariès, Philiph (1987). El niño y la vida familiar en el Antiguo Régimen. Madrid: Taurus.

Arroñada, Silvia N. (1997). Aproximación a la vida de los niños en la Baja Edad Media. Meridies, IV, pp. 57-69.

Arroñada, Silvia N. (2002). Algunas reflexiones sobre la infancia (siglos XIII al XV). Meridies, V-VI, pp. 223-242.

Barquero, Aurelio (1952). Bosquejo histórico del Hospital Real y General de Nuestra Señora de Gracia de Zaragoza. Zaragoza: Institución Fernando el Católico.

34 Justo lo contrario a la situación extrema que conlleva la 'desafiliación', institución practicada ya desde el siglo XII, con causas y efectos justificables sólo por su excepcionalidad y que entrañaba tanto la ausencia de patria potestad y la responsabilidad de los padres por actos de sus hijos como la desheredación (Delgado Echevarría, 2001-2002 y Gómez de Valenzuela 2018). 
Jóvenes huérfanos en el Maestrazgo medieval... - J. Aparici y C. Villanueva

Becchi, Egle y Julia, Dominique (eds) (1998). Histoire de l'enfance en Occident. Tome I: De l'Antiquité au XVII' siècle. París: Seuil.

Boswell, John (1998). The kindness of strangers. The abandonment of children in western Europa from late Antiquity to Renaissance. Chicago: Chicago University Press.

Carreres Zacarés, Salvador (1936). Lafermamossos, institució valenciana del segle XV. En Homenatge a Antoni Rubió i Lluch, 1, Barcelona, pp. 255-266.

Castillo Peiró, Jaime (1997). Una obra cristiano-social valenciana del siglo XV, presente en nuestro tiempo: el Colegio Imperial de Niños Huérfanos de San Vicente Ferrer. Memoria ecclesiae, 11. Actas del XI Congreso de la Asociación de Archiveros de la Iglesia en España (segunda Parte), pp. 439-453.

Furió Diago, Antoni (1990). Tierra, familia y transmisión de la propiedad en el País Valenciano durante la baja edad media. En Pastor, Reina (dir.) Relaciones de poder, de producción y parentesco en la edad media y moderna. Madrid: CSIC, pp. 305-328.

Delgado Echevarría, Jesús (2001-2002). El «desafillamiento» en el derecho aragonés. Revista de derecho civil aragonés, 7-8, pp. 23-46.

De Sousa, João Silva (1980). Tutorias e curadorias: achegas para o estudo da tutela e administraçao dos bens de menores e inabilitados na Idade Média. Arquipélago. Série Ciências Humanas, 2, s. p.

Forns de Rivera, Cristina (1997). El ejercicio de la tutela por las mujeres de los ciudadanos de Barcelona (siglos XIII-XIV). En Historia de la mujer e historia del matrimonio. Congreso Internacional Historia de la Familia: Nuevas perspectivas sobre la sociedad europea (Murcia 1994) [2a Sesión]. Murcia: Universidad, pp. 53-63.

García Fernández, Máximo (2019). Los caminos de la juventud en la Castilla moderna. Menores, huérfanos y tutores. Madrid: Sílex.

García Herrero, María del Carmen (1998). Elementos para una historia de la infancia y de la juventud a finales de la Edad Media. En La vida cotidiana en la Edad Media: Actas de la VIII Semana de Estudios Medievales. Logroño: Instituto de Estudios Riojanos, pp. 223-252.

Garcia-Oliver, Ferran (2017). Élites campesinas en el entorno de la ciudad de Valencia: los Castrellenes. Studia historica. Historia medieval, 35/2, pp. 119-144.

Gómez de Valenzuela, Manuel (2018). Documentos sobre el desafillamiento en Aragón en los siglos XV y XVII. Revista de derecho civil aragonés, 24, pp. 89-124.

Grau, Sergi; Berga, Eduard y Cingolani, Stegano (2015). L'herètica pravitat a la Corona d'Aragó. Documents sobre càtars, valdesos i altres heretges (1155-1324). Barcelona: Fundació Noguera.

Guinot Rodríguez, Enric (1988). Demografia medieval del nord del País Valencià. En Actes de les I Jornades d'Estudis sobre la Població del País Valencià, Valencia, 1988, pp. 229-249. 
Guinot Rodríguez, Enric (1992-93). La ramaderia al Maestrat Medieval: entre l'expansió i la crisi. Estudis Castellonencs, 5. Diputació de Castelló, pp. 255-274.

Guinot Rodríguez, Enric y Furió Diago, Antoni (1980). Un exemple deconomia domèstica de principis del XVè. L’administració d'una tutela. Sueca 1412-1427. Quaderns de Cultura de Sueca, 1, pp. 11-46.

Heywood, Colin (2001). A History of Childhood: Children and Childhood in the West from Medieval to Modern Times. Cambridge: Polity.

Illanes Zubieta, Ximena (2019). En manos de otros. Infancia y abandono en la Barcelona del siglo XV. Santiago de Chile: Ediciones Universidad Católica de Chile.

Levi, Enzo (1932). Pittori e mercanti in terra di pastori. Boletín de la Sociedad Castellonense de Cultura, 13, pp. 39-48.

Levi, Giovanni y Schitt, Jean Claude (eds.) (1996). Historia de los jóvenes, I. De la Antigüedad a la Edad Moderna. Madrid: Taurus.

Marino, Salvatore (2019). El Memorial dels Infants. Edició crítica d'una font per a l'estudi de la infància a la Barcelona del segle XV. Barcelona: Fundació Noguera.

Melis, Federigo (1985). La llana de l'Espanya mediterrània i de la Berberia Occidental en els segles XIV-XV. En Furió, Antoni (dir). València, un mercat medieval. Valencia, pp. 63-80.

Merchán Álvarez, Antonio (1976). La tutela de los menores en Castilla hasta fines del siglo $X V$. Sevilla: Universidad de Sevilla.

Motis Dolader, Miguel Ángel (1992). Consuetudine regni non habemus patriam potestatem. Un supuesto de tutela y curatela en la judería de Daroca en el siglo XV. Ius fugit, 1, pp. 79-138.

Navarro Espinach, Germán (1993). Aprendices textiles en Valencia medieval. Los contratos del padre de huérfanos Tomás Oller (1461-1468). En Actas del II Congreso de Jóvenes Historiadores y Geógrafos (Montcada, 1992), Valencia, 1993, pp. 141-147.

Navarro Espinach, Germán (2000). El Hospital de Santa María de Villaespesa y de San Juan Bautista en la ciudad de Teruel a través de los actos notariales de Alfonso Jiménez (1481-1518). Aragón en la Edad Media, 16, pp. 565-590.

Navarro Espinach, Germán (2004). Las etapas de la vida en las familias artesanas de Aragón y Valencia durante el siglo XV. Aragón en la Edad Media, 18, pp. 203-244.

Obarrio Moreno, Juan Alfredo (2012). La edad pupilar y la mayoría de edad en la Valencia medieval. Anuario de Estudios Medievales, 42/2, CSIC, pp. 771-797.

Ocón Domingo, José (1995). La situación social de la infancia durante la Edad Media. En Vega Rodríguez, María Teresa y Tabernero Urbieta, María del Carmen (coord.), Psicología social de la educación y de la cultura, Salamanca: Eudema, pp. 69-73.

Orme, Nicholas (2001). Medieval Children. New Haven-Londres, Yale University Press. 
Jóvenes huérfanos en el Maestrazgo medieval... - J. Aparici y C. Villanueva

Rabassa Vaquer, Carles (1993). El comercio de la lana. En Historia de Castellón, vol. I. Castellón: Levante, pp. 246-249.

Rabassa Vaquer, Carles (2006). La manufactura tèxtil en l’àmbit rural dels Ports de Morella (segles XIV-XV). Millars, Espai i Història, 29. Castelló, Universitat Jaume I, pp. 151-173.

Rossi, Maria Clara y Garbellotti, Marina (eds.) (2015). Adoption and Fosterage Practices in the Late Medieval and Modern Age. Roma: Viella.

Rossi, Maria Clara; Garbellotti, Marina y Pellegrini, Michele (eds.) (2014). Figli delezione. Adozione e affidamento dallétà antica alletà moderna. Roma: Carocci.

Royo García, Juan Ramón (1994). Los Hospitalicos de niños y niñas de Zaragoza en 1605 según la visita del arzobispo Tomás de Borja. Revista de historia Jerónimo Zurita, 69-70, pp. 115-128.

Royo Pérez, Vicent (2016). Villafranca (1239-1412): conflictes, mediacions de pau i arbitratges en una comunitat rural valenciana. Castelló: Universitat Jaume I.

Rubio Vela, Agustín (1990). Infancia y marginación. En torno a las instituciones trecentistas valencianas para el socorro de los huérfanos. Revista d'Hisloria Medieval, 1, pp. 111-153.

San Vicente Pino, Ángel (1965). El oficio de Padre de Huérfanos en Zaragoza, Zaragoza: Institución Fernando el Católico.

San Vicente Pino, Ángel (2008). Recuerdos y remiendos de una tesis doctoral sobre el oficio concejil de Zaragoza llamado «padre de los huérfanos». Aragón en la Edad Media, 20, pp. 723-736.

Sánchez Adell, José (1995). Aportaciones a la historia de la ganadería medieval en las comarcas del norte castellonense (Ports de Morella, Benifaçà y Maestrazgo de Montesa). Boletín de la Sociedad Castellonense de Cultura, 71/4, pp. 445-487.

Shahar, Shulamith (1990). Childhood in the Middle Ages. Londres, Routgledge.

Taraçona, Pere Jeroni (1580). Institucions dels furs i privilegis del Regne de València. Valencia.

Villagrasa Elías, Raúl (2016). La red de hospitales en el Aragón medieval (ss. XII-XV). Zaragoza, Institución Fernando el Católico.

Vinyoles Vidal, Teresa y González Betlinksi, Margarida (1982). Els infants abandonats a les portes de l'Hospital de Barcelona (1426-1439). En Riu, Manuel (dir.). La pobreza y la asistencia a los pobres en la Cataluña medieval: volumen misceláneo de estudios $y$ documentos, II. Barcelona: CSIC-IMF, pp. 191-285.

2285.misceláneo de estudios y documentos, II. Barcelona: CSIC-IMF, pp. 191-285. 